\title{
INTERFERON BETA-1A-INDUCED DEPRESSION AND SUICIDAL IDEATION IN MULTIPLE SCLEROSIS
}

\author{
Marco Aurélio Lana-Peixoto ${ }^{1}$, Antônio Lúcio Teixeira Jr. ${ }^{2}$, Vitor Geraldi Haase ${ }^{3}$
}

\begin{abstract}
Depression and suicide have been reported in association with multiple sclerosis (MS). Some studies show that interferon beta may increase the depression rate. We report a case of depression and suicidal ideation in coincidence with the start of increased doses of interferon beta-1a and their complete reversal following the drug withdrawal. The patient was a 21-year-old man with MS and no past history of affective disorders who was given interferon beta-1a in the dose of $11 \mu \mathrm{g}$ three times per week. As a new relapse occurred the dose of interferon beta-1a was increased to $22 \mu \mathrm{g}$ three times a week. The patient then observed increased worry, irritability and a sense of discouragement as well as recurring suicidal thoughts. His mood was rapidly restored following interferon beta-1a withdrawal. This case suggests that patients with MS may develop depression and suicidal thoughts when treated with high doses of interferon beta-1a.
\end{abstract}

KEY WORDS: multiple sclerosis, interferon beta-1a, depression, suicidal ideation.

\begin{abstract}
Depressão e idéias suicidas induzidas por interferon beta-1a na esclerose múltipla
RESUMO - Depressão e idéias suicidas são relatados na esclerose múltipla (EM). Alguns estudos demonstram que interferon beta pode aumentar sua freqüência. Relatamos o caso de um jovem de 21 anos com EM, sem história pregressa de distúrbios psiquiátricos, que vinha usando interferon beta-1a na dose de $11 \mu \mathrm{g}$ três vezes por semana, com boa tolerância. A dose foi aumentada para $22 \mu \mathrm{g}$ três vezes por semana após um novo surto. 0 paciente observou o aparecimento de fenômenos depressivos e idéias suicidas coincidindo com o aumento da dose. A suspensão da droga foi acompanhada de desaparecimento completo desses sintomas. Seis meses após a retirada do interferon beta-1a, o paciente se encontra em uso de acetato de glatiramer, não tendo mais apresentado qualquer fenômeno depressivo ou pensamentos suicidas. Este caso sugere que pacientes com EM podem desenvolver depressão e pensamentos suicidas quando tratados com doses elevadas de interferon beta-1a.
\end{abstract}

PALAVRAS-CHAVE: esclerose múltipla, interferon beta-1a, depressão, idéias suicidas.

Although affective symptoms in multiple sclerosis (MS) have been noticed since its clinical characterization by Charcot ${ }^{1}$ only in the last two decades more detailed studies dealing with their prevalence, causality, profile and treatment have been carried out $t^{2-9}$. Depressive symptoms of sufficient severity and duration to warrant a diagnosis of major depression affect 25 to $50 \%$ of MS patients during the course of disease ${ }^{2,3}$. This rate is higher than that found in both the general population and patients with other disabling neurological conditions such as amyotrophic lateral sclerosis, temporal lobe epilepsy, muscular dystrophy and spinal cord trauma ${ }^{2,4,5}$.

The clinical heterogeneity of depression, which includes symptoms of a variety of intensity such as transient changes in mood, adjustment disorders to life events, dysthymia, and major depression, as well as their overlapping with MS more well-defined somatic symptoms such as fatigue and sleeplessness might make one supposes that the frequency of depression has been overestimated ${ }^{10}$. Nevertheless some studies have shown that, even when these associated somatic symptoms are appropriately controlled, depression in MS patients remains highly prevalent ${ }^{5,11}$. In addition to that, major depression in these patients is mainly characterized by anger, irritability and worry rather than apathy, withdrawal, feeling of guilt and worthlessness, usually found in uncomplicated major depression ${ }^{2,11}$. Likewise, suicide, attempted suicide and suicidal ideation occur more frequen-

CIEM Minas Gerais Center for Investigation of Multiple Sclerosis, Federal University of Minas Gerais Medical School, Belo Horizonte MG, Brazil; and the Brazilian Committee for Treatment and Research in Multiple Sclerosis (BCTRIMS): ${ }^{1}$ Associate Professor of Neurology and Ophthalmology; ${ }^{2}$ Resident in Neurology; ${ }^{3}$ Associate Professor of Neuropsychology.

Received 31 January 2002, received in final form 13 May 2002. Accepted 21 May 2002.

Dr. Marco A. Lana-Peixoto - Rua Padre Rolim 769 / 1301-1304 - 30130-090 Belo Horizonte MG - Brasil. FAX: 553132223935.

E-mail:lanapma@uol.com.br 
tly in MS than in the general population ${ }^{11,12}$ adding concern to the need for early identification of predictive and exacerbating factors as well as appropriate management. Although interferon beta has been widely prescribed for treatment of patients with relapsing forms of MS the issue of depression and suicidal ideation as one of its side effects has not been fully clarified yet.

Herein we report a case of depression and suicidal ideation occurring in coincidence to increased dose of interferon beta-1a, and their rapid and complete remission following the drug withdrawal and change in therapeutic regimen.

\section{CASE}

A 16-year-old white man presented with sudden-onset loss of vision in the right eye associated with pain exacerbated by eye movements. His past history and family history were unremarkable for ophthalmologic, neurological or mental disorders. Examination at that time showed that the visual acuity was finger-counting in the right eye and $20 / 20$ in the left eye. There was a marked afferent pupillary defect and the fundi examination was unrevealing. A comprehensive laboratory work-up including blood cell count, blood chemistry, ESR, antinuclear antibodies, serology for syphilis, HIV, HTLV I-II, CMV, herpes simplex virus and varicella-zoster virus, toxoplasmosis, CSF examination and tuberculin test yielded negative results. A brain magnetic resonance imaging (MRI) was also normal. The patient was treated with intravenous high doses of methylprednisolone and had full recovery of vision. He did well for two years when developed dysesthesia below T4-level, Lhermitte's symptom and upper extremity ataxia. A neurological examination revealed visual acuity 20/30 in the right eye and $20 / 20$ in the left eye. The right optic disc was moderately pale and there were upper limb dysmetria, decreased tactile and pain sensation in the upper and lower extremities, absent vibration sense in the lower limbs and decreased position sense in the toes. The gait was normal. A new brain MRI disclosed T2-hyperintense lesions in the corpus callosum and white matter of the frontal lobes, right temporal lobe, right parietal lobe and both occipital lobes. A cerebrospinal fluid examination disclosed 7 lymphocytes per cubic millimeter, protein $40 \mathrm{mg} \%$, glucose $70 \mathrm{mg} \%$ and $\mathrm{lgG}$ index 0.92 . The patient was given IV methylprednisolone and was started on subcutaneous interferon beta-1a $11 \mu \mathrm{g}$ three times per week. Again he had full recovery. He did well for three years with good tolerance to the interferon beta-1a therapy, when a new relapse characterized by vertigo and ataxia occurred. The dose was then increased to $22 \mu \mathrm{g}$ three times per week. A few weeks later he started complaining of marked worry about his disease, increased irritability, feeling of anger, sense of discouragement and recurring suicidal thoughts. He denied fatigue, sleep or appetite disturbance. Repeated neurological examination and brain MRI study failed to reveal any new finding. Interferon beta-1a withdrawal rapidly restored his mood. He has been now on glatiramer acetate for over six months and depressive symptoms and suicidal ideation have not recurred.

\section{DISCUSSION}

The present case highlights the association between MS and depressive symptoms and may even suggest that major depression and suicidal ideation were caused or triggered by the increase in interferon beta-1a dose. The patient had no previous or family history of depression and had been adequately coping with his disease until the dose of interferon beta- 1 a was increased to $22 \mu \mathrm{g}$ three times per week. Additional evidences supporting the relationship of depressive symptoms to the increased dose of interferon beta- $1 \mathrm{a}$ include absence of change in the neurological disability status as measured by the EDSS at the time of the onset of depression, absence of fatigue as an associated symptom, no new lesions on a repeated brain $\mathrm{MRI}$, and the complete disappearance of the depressive symptoms immediately following the drug withdrawal.

There are several convincing trials demonstrating that interferon beta and more recently glatiramer acetate decrease the frequency of MS relapses by approximately $30 \%$, significantly reduce the burden on total lesion load in the brain and show a trend toward a delay in the progression of disability ${ }^{13}$. Although some investigators ${ }^{14,15}$ have reported depressive symptoms as a side effect in MS patients on treatment with interferon beta the issue still remains controversial. In the pivotal study with interferon beta- $1 \mathrm{~b}$ four patients attempted and one completed suicide over the course of five years in contrast with no such events in the placebo group ${ }^{15}$. On the other hand, some investigators failed to demonstrate a clear relationship between depression and interferon beta therapy for MS. In a series of 90 patients followed over 24 months, Borras et al. ${ }^{16}$ found improvement in mood and anxiety. Likewise the European study on interferon beta 1-b in secondary progressive MS showed depression occurring more commonly in the control group than in treated patients ${ }^{17}$. Data from the PRISMS clinical trial revealed that depression rates in patients treated with $22 \mu \mathrm{g}, 44 \mu \mathrm{g}$ or placebo three times per week were comparable at 12,18 and 24 months and the proportion of patients with depression was strongly associated with pre-treatment depression levels ${ }^{18}$. Mohr et al. ${ }^{19}$ had already shown that increases in depression after initiation of interferon beta 1-a treatment were related to pre-treatment levels. They sug- 
gest that physicians should closely monitor their patients with recent history of depressive symptoms, regardless of their current mental status, as the risk of major depression is increased in the first months of treatment.

Previous studies have documented depressive symptoms in patients receiving high-dose interferon alpha as treatment for malignant melanoma and chronic hepatitis $\mathrm{C}^{20}$. Suicidal ideation and many cases of suicide have been also reported ${ }^{21}$.

Depression and fatigue were found to be related significantly to discontinuation of treatment both in patients receiving alpha or beta interferon. During the first three months of interferon alpha therapy for malignant melanoma $45 \%$ of the patients developed major depression, and more than one third of them had to discontinue treatment ${ }^{20}$. Pretreatment with the antidepressant paroxetine significantly reduced the incidence of major depression and helped patients to remain on treatment ${ }^{20}$. Similarly, in a series of 85 patients treated with interferon beta- $1 a$ for MS Mohr et al. ${ }^{22}$ observed new or increased depression in $41 \%$ of them within six months of therapy. They also noticed that antidepressant drugs and psychotherapy helped patients with depression to remain on treatment.

The mechanisms by which interferon beta causes depression are still unclear. It is well known that interferon alpha induces the production of pro-inflammatory cytokines such as tumor necrosis factor- $\alpha$, interleukin- 1 and interleukin-6, all of which are potent inducers of sickness behavior and neurotoxic effects $^{23}$. It is likely that similar effects can be also produced by interferon beta. An immune dysregulation has been recently associated with mood and cognitive changes in $\mathrm{MS}^{24}$.

Anatomical correlates of depression in MS patients have not been well defined. Although some investigators have failed to demonstrate an association between the presence of MRI abnormalities and affective symptoms, others have found association between depression and temporal lobe involvement $^{7,25}$ lesions in the right parietal region ${ }^{26}$, the left frontal lobe ${ }^{27}$, the left arcuate fasciculus ${ }^{8,9}$ or the total lesion load ${ }^{28}$. Additionally, a disconnection between subcortical and cortical areas connected to the limbic system has been proposed ${ }^{9}$. In a recent comparative study of lesion patterns in 31 patients with MS and depression as opposed to $47 \mathrm{MS}$ patients without depression, Berg et al. ${ }^{7}$ found that the most significant difference was observed in the temporal lobes with depressed patients having a higher lesion load than non-depressed patients. Differences were also significant for lesion load in the right parietal lobe, and a trend was found for lesions in the right frontal lobe, total lesion load and lesion load of the cerebellum. They emphasize that the areas with higher lesion load are projection areas of the basal-limbic system, giving support to Sabattini et al.' ${ }^{8}$ suggestion that depression in MS could be caused by a disconnection of subcortical and cortical areas involved in limbic system functions. Significant correlation was seen between severity of depression and the lesion load in the temporal lobes, more marked in the right side. Transcranial sonography provided no evidence for structural abnormalities of the ponto-mesencephalic midline as has been seen in patients with unipolar depression as well as in Parkinson's disease patients with depression ${ }^{29,30}$.

As depression adds morbidity to MS, increased risk of suicide may turn it still more dramatic. Since Kahana et al. in $1971^{31}$ reported that $3 \%$ of his 295 patients committed suicide in contrast with $0.1 \%$ rate observed in the general population ${ }^{32}$ a widespread concern has arisen. In a study of 5525 MS patients Stenager et al. ${ }^{33}$ reported a significantly elevated suicide rate, with males and patients under 30 years most at risk. In a study on causes of death in 3126 MS patients Sadovnick et al. ${ }^{12}$ found suicide accounting for $15 \%$ of all ascertained deaths. A reduction in serotonergic activity has been demonstrated in MS and non-MS patients who were depressed and committed suicide ${ }^{34}$ and a decreased nocturnal secretion of melatonin - which derives from serotonin - has been found in MS patients with suicidal ideation or intent ${ }^{35}$.

Early identification of depressive symptoms in MS patients or identification of which patients are more vulnerable to depression during interferon beta treatment could provide physicians with efficient therapy strategies. Antidepressants agents, such as tricyclics, fluoxetine and selective serotonin-reuptake inhibitors, may be effective in the prophylaxis and treatment of depressive symptoms in MS and interferon-associated depression ${ }^{11,21}$. Other forms of treatment include psychotherapy and cognitive-behavior therapy ${ }^{11}$.

Although there is no consensus regarding withdrawal of interferon beta when MS patients develop depression, the suicidal ideation in our patient was worrisome enough to prompt a change in the therapy. So far studies on glatiramer acetate in MS have not shown any deleterious effect in mood making it a safer drug in MS patients with affective disorders, 
or in cases like ours, of interferon therapy-related depression. Physicians prescribing interferon beta for MS treatment should be alert to the occurrence of depressive symptoms and suicidal thoughts in their patients which may add suffering to this disabling condition.

\section{REFERENCES}

1. Stenager E. Historical and psychiatric aspects of multiple sclerosis. Acta Psychiatr Scand 1990;84:398.

2. Minden SL, Schiffer RB. Affective disorders in multiple sclerosis: review and recommendations for clinical research. Arch Neurol 1990;47:98-104

3. Sadovnik AD, Remick RA, Allen J, et al. Depression and multiple sclerosis. Neurology 1996;46:628-632.

4. Schiffer RB, Babigian HM. Behavioral disorders in multiple sclerosis, temporal lobe epilepsy, and amyotrophic lateral sclerosis: an epidemiologic study. Arch Neurol 1984;41:1067-1069.

5. Minden SL, Orav J, Reich P. Depression in multiple sclerosis. Gen Hosp Psychiatry 1987;9:426-434.

6. Zorzon M, Masi R, Nasuelli D, et al. Depression and anxiety in multiple sclerosis: a clinical and MRI study in 95 subjects. J Neurol 2001;248:416-421.

7. Berg RM, Supprian T, Thomae J, et al. Lesion pattern in patients with multiple sclerosis and depression. Mult Scler 2000;6:156-162.

8. Sabatini U, Pozzilli C, Pantano P, et al. Involvement of the limbic system in multiple sclerosis patients with depressive disorders. Biol Psychiatry 1996;39:970-975.

9. Pujol J, Bello J, Deus J, Marti-Vilalta JL, Capdevila A. Lesions in the left arcuate fasciculus of magnetic resonance imaging with neuropsychological testing in multiple sclerosis. Neurology 1997;49:1105-1110.

10. Feinstein A. Multiple sclerosis, disease modifying treatments and depression: a critical methodological review. Mult Scler 2000;6:343-348.

11. Feinstein A. The clinical neuropsychiatry of multiple sclerosis. Cambridge: University Press, 1999:26-50.

12. Sadovnick AD, Eisen K, Ebers GC, Patty DW. Cause of death in patients attending multiple sclerosis clinics. Neurology 1991;41:1193-1196.

13. Noseworthy JH, Lucchinetti C, Rodriguez M, Weinshenker BG. Multiple sclerosis. N Engl J Med 2000;343:938-952.

14. Neilley LK, Goodin DS, Goodkin DE, Hauser SL. Side effect profile of interferon beta-1b in MS: results of an open label trial. Neurology 1996;46:552-554.

15. The INFbeta Multiple Sclerosis Group. Interferon beta-1b is effective in relapsing-remitting multiple sclerosis: 1 . Clinical results of a multicenter, randomized, double-blind, placebo controlled trial. Neurology 1993;43:655-661.

16. Borras C, Rio J, Porcel J, et al. Emotional state of patients with relapsingremitting MS treated with interferon beta-1b. Neurology 1999;52:1636-1639.
17. European Study Group on Interferon beta-1b in Secondary Progressive MS. Placebo-controlled multicentre randomised trial of interferon beta$1 \mathrm{~b}$ in treatment of secondary progressive multiple sclerosis. Lancet 1998;352:1491-1497.

18. Patten SB, Metz LM. Interferon beta-1a and depression in relapsingremitting multiple sclerosis: an analysis of depression data from PRISMS clinical trial. Mult Scler 2001;7:243-248.

19. Mohr DC, Likosky W, Dwyer P, et al. Course of depression during the initiation of interferon beta-1a treatment for multiple sclerosis. Arch Neurol 1999;56:1263-1265.

20. Musselman DL, Lawson DH, Gumnick JF, et al. Paroxetine for the prevention of depression induced by high-dose interferon alfa. N Engl J Med 2001;344:961-966.

21. Janssen HLA, Brouwser JT, van der Mast RC, Schalm SW. Suicide associated with alfa-interferon therapy for chronic viral hepatitis. J Hepatol 1994;21:241-243.

22. Mohr DC, Goodkin DE, Likosky W, et al. Treatment of depression improves adherence to interferon beta- $1 \mathrm{~b}$ therapy for multiple sclerosis. Arch Neurol 1997;54:531-533.

23. Licinio J, Kling MA, Hauser P. Cytokines and brain function: relevance to interferon-alpha-induced mood and cognitive changes. Semin Oncol 1998;25(Suppl 1):30-38.

24. Foley FW, Traugott U, LaRocca NG, et al. A prospective study of depression and immune dysregulation in multiple sclerosis. Arch Neurol 1992;55:238-244.

25. Honer WG, Hurwitz T, Li DKB, Palmer M, Paty DW. Temporal lobe involvement in multiple sclerosis patients with psychiatric disorders. Arch Neurol 1987;44:187-190.

26. Rao SM, Leo GJ, Haughton VM, et al. Workshop on neurobehavioral disorders in multiple sclerosis. Arch Neurol 1993;50:658-662.

27. Absher JR. Clinico-analysis of patients with multiple sclerosis and depression. Neurology 1990;49:305-381.

28. Reischies FM, Baum K, Brau H, et al. Cerebral magnetic resonance imaging findings in multiple sclerosis: relation to disturbance of affect, drive and cognition. Arch Neurol 1988;45:1114-1116.

29. Becker G, Truck U, Bogdahn U, Becker T. Echogenicity of the brainstem raphe in patients with major depression. Psychiatry Res Neuroimaging 1994;55:75-84.

30. Becker T, BeckerG, Seufert J,HofmannE. Parkinson's disease and depression: evidence for an alteration of the basal limbic system detected by transcranial sonography. J Neurol Neurosurg Psychiatry 1997;63:590-596.

31. Kahana E, Leibowitz U, Alter M. Cerebral multiple sclerosis. Neurology 1971;21:1179-1185.

32. Paykel ES, Myers JK, Lindethall JJ, Tanner J. Suicidal feelings in general population: a prevalence study. Br J Psychiatry 1974;124:460-469.

33. Stenager EN, Stenager E, Henrikson NK, et al. Suicide and multiple sclerosis: an epidemiological investigation. J Neurol Neurosurg Psychiatry 1992;55:869-876.

34. Roos BE. 5-Hydroxyindolacetic acid and homovanillic acid in cerebrospinal fluid of patients with neurological disease. Eur Neurol 1974;11:37-45.

35. Sandyk R, Awebuch G. Nocturnal melatonin secretion in suicidal patients with multiple sclerosis. Int J Neurosci 1993;71:173-182. 